\title{
How to make opinion leaders and influence people
}

A $\mathrm{t}$ face value, a key opinion leader (or more commonly "KOL") in medicine is an influential physician or researcher who is held in high esteem by their colleagues. The term originates from studies of influence in the 1940s by communications theorist Paul Lazarsfeld, who was skeptical about how much the mass media directly shaped the public's views. He and his students established that, in some areas, people changed their views and preferences more because of trusted figures in their networks - or "opinion leaders" - than because of forces such as advertising. Lazarsfeld's group extended their argument to medicine in the mid-1950s through a study contracted by Pfizer about what influenced doctors in the United States to adopt a new drug; the study was later published as the book, Medical innovation: a diffusion study. ${ }^{1}$

The term KOL has taken up residence in medicine and, in particular, is associated with the pharmaceutical industry. Pharmaceutical companies have steadily increased their use of the KOL model of communication since the late 1950s. Data obtained under the US Physician Payments Sunshine Act for the last five months of 2013 show that drug companies made 55000 payments of $\$ 400.00$ or more for what appear to be speakers' fees (http://cms.gov/openpayments/). An earlier survey reported that over 141000 physicians (one in every six) in the US had been a paid speaker for a pharmaceutical company. ${ }^{2}$ The situation in Canada and elsewhere is probably similar. To be clear, there have been fully independent attempts to leverage the opinion leader concept with the aim of improving the dissemination of research and, thus, medical practice, by using influential physicians to educate their peers. ${ }^{3}$ However, today it is uncommon to hear somebody referred to as a KOL if they do not have a relationship with at least one pharmaceuti-

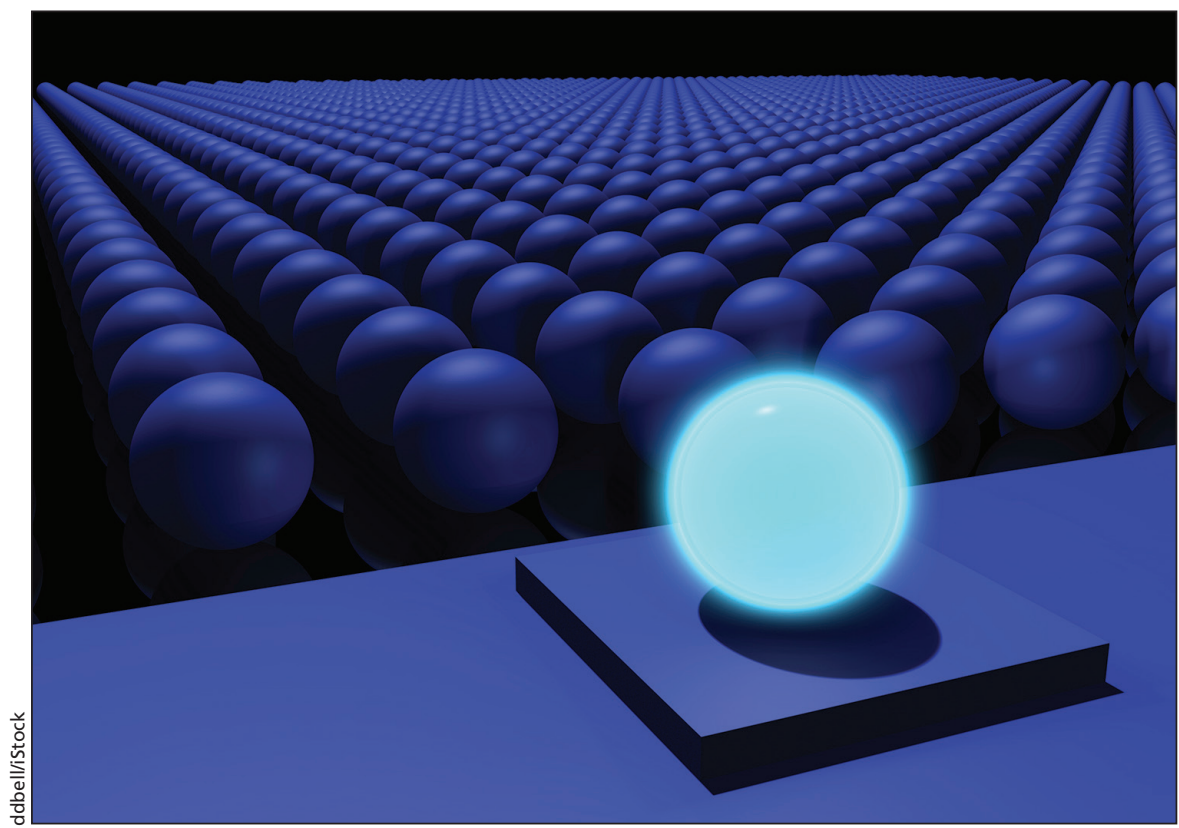

cal company. The connection is strong enough that, in one recent industry poll, more than $60 \%$ of doctors (http://www .pharma-mkting.com/news/PMNissue V1403Apr2015archive.htm) thought that the term KOL should be replaced because of its association with the pharmaceutical industry.

\section{KOL management}

KOLs may be more or less "key" and need not be existing leaders of opinion. Some are clinicians who earn extra income from talks for pharmaceutical companies. Others are well-known researchers who have authored hundreds of publications.

Companies put low-level KOLs on speaker bureaus and hire them to give lunchtime, after-dinner and similar scripted information sessions on a particular drug, ${ }^{4}$ the talks are tailored both to conform to legal or regulatory demands and to be effective promotional tools. For major programs, KOLs receive training on particular studies and how to present them. For example, one marketing firm's website states that "[i]t's vital that advocates are able to communicate and influence colleagues with clarity and conviction. To ensure speakers are at the top of their game, we have developed a communication skills programme for clinicians." Companies engage in detailed data analytics to establish the effectiveness of their speaker bureaus and sometimes measure the number of prescriptions written for a drug before and after a talk. Understandably, promotion via speaker bureaus has been strongly criticized.

The industry puts high-level KOLs in more varied roles. A medical director for a small pharmaceutical company lists the functions and "touch points" to build strong connections between highlevel KOLs and her company: "advisory boards and scientific summits, internal training, consultants, publications, media activities, speaking at local and national meetings, congresses, peerto-peer communications, patient communications and education, and policy, advocacy and social media activity." 6 The KOLs may even be offered authorship on manuscripts stemming from 
company research. Typically, these manuscripts are sent to their multiple authors fully analyzed and well written; therefore, the only substantial input needed is approval. ${ }^{7}$

To help with KOL management (a standard industry term), there are firms that provide lists of potential KOLs for pharmaceutical company projects, design plans for interactions, integrate those plans with publication plans and train KOLs in public speaking. One pharmaceutical marketing firm stated that KOL is "a convenient shorthand for those people - usually eminent, usually physicians - who we co-opt into our development and marketing strategies."

\section{Making KOLs}

Interestingly, reanalysis of the original data showed that the 1950s Medical Innovation study did not support the conclusion that physicians in that era were influenced by local opinion leaders. ${ }^{8}$ This does not mean that KOLs are ineffective today; after all, companies track prescriptions and measure the influence of the KOLs on sales. How could the industry have built a successful marketing model on a misunderstanding? It achieved success by changing the social landscape of communication in medicine.

The industry has fortified the importance of opinion leaders within medicine. Since the 1950s, scientific presentations in clinics and at dinner events have become common and an ordinary way to communicate information and influence opinion. Sponsored conferences, grand rounds and continuing medical education (CME) presentations by research stars and rising stars also have become normalized. Reprinted journal articles by those same stars are given to physicians in large numbers, and this information is highly valued. Peer-to-peer dissemination of information and modeling of practice is effective.

In addition, the industry use of KOLs makes individual would-be opinion leaders stand out, which heightens their career trajectory and success. To its speakers the industry gives training, talks, platforms, audiences and sometimes authorship opportunities, which is exactly the prominence they need to shape opinions and speak in an authoritative language.

\section{KOL influence}

KOLs seem to believe the scientific data they present and to trust in the efficacy of products they promote: they see themselves as providing necessary and important education. The companies that hire them would not have it any other way: the appearance of conviction and integrity are crucial to making the KOLs persuasive role models for changing the prescribing habits of other physicians.

Anecdotally, audience members at promotional talks trust their own astuteness regarding bias but believe other physicians are more credulous; this is consistent with attitudes about conflicts of interest in general. ${ }^{9}$ However, surveys have shown that physicians generally do not report commercial bias in sponsored $\mathrm{CME}$ and other presentations.

$\mathrm{KOL}$ integrity is not enough to avoid co-option. As part of their recruiting and education process, companies go to some lengths to strongly influence the actions, habits, beliefs and loyalties of the physicians and researchers with whom they engage. KOLs and the data they present are managed as much as possible, and to the extent that these efforts are successful, KOLs are an integral part of promotional plans. KOLs also tend to be high prescribers: the first targets of their influence are often themselves. ${ }^{10}$

When KOLs insist that their talks are supported by scientific evidence, they overlook how the science in question is "interested," and that sometimes the careful deployment of science can support commercial over patient interests. When drug companies pay KOLs to be information conduits, it is the companies' preferred information being circulated. The way information is framed, the questions being asked, the particular results being presented and the analyses given are all chosen with commercial goals in mind. The result may be recognizable as medical science, but it is science serving very narrow interests. When they present scientific evidence for drugs and diseases, KOLs can do commercially effective work under the guise of science and medical expertise, which downplays the company interests. Marketers describe KOLs as part of the "activation networks" for drugs.
Just as companies devote considerable attention to managing KOLs, they also put effort into creating seemingly appropriate presentations, ones that include arguments for easyto-remember and timely messages that will help convince physicians to prescribe their products. The companies frequently measure the effectiveness of their programs to track the return on their investments.

What is communicated will often be sound medical science and will not challenge the KOLs' senses of integrity or the audiences' senses of appropriateness; nevertheless, it will be science chosen to help sell a product. In the end, it matters little what KOLs paid by the pharmaceutical industry think they are doing, how honest they are or how much they believe what they say. They are, inevitably and inescapably, part of largescale, commercially driven efforts to shape the views physicians have and apply in practice. In effect, KOLs mediate between pharmaceutical companies and important audiences: they are hired or wooed because of their potential to as the term indicates — lead opinions.

\section{Sergio Sismondo PhD}

Department of Philosophy, Queen's

University, Kingston, Ont.

\section{References}

1. Coleman JS, Katz E, Menzel H. Medical innovation: a diffusion study. Indianapolis: Bobbs-Merrill; 1966.

2. Campbell EG, Gruen RL, Mountford J, et al. Blumenthal. A national survey of physician-industry relationships. N Engl J Med 2007;356:1742-50.

3. Lomas J, Enkin MW, Anderson GM, et al. Opinion leaders vs. audit and feedback to implement practice guidelines: delivery after previous cesarean section. JAMA 1991;265:2202-7.

4. Reid L, Herder M. The speakers' bureau system: a form of peer selling. Open Med 2013;7:2-e31.

5. Moynihan R. Key opinion leaders: independen experts or drug representatives in disguise? $B M J$ 2008;336:1402-3.

6. Meffert J. Key opinion leaders: where they come from and how that affects the drugs you prescribe. Dermatol Ther 2009;22:262-8.

7. Sismondo S. Ghosts in the machine: publication planning in the medical sciences. Soc Stud Sci 2009; 39:171-98.

8. Van den Bulte C, Lilien GL. Medical innovation revisited: social contagion versus marketing effort. Am J Sociol 2001;106:1409-35.

9. Sah S, Fugh-Berman A. Physicians under the influence: social psychology and industry marketing strategies. J Law Med Ethics 2013;41:665-72.

10. Fugh-Berman A, Ahari S. Following the script: how drug reps make friends and influence doctors. PLoS Med 2007;4:e150.

CMAJ 2015. DOI:10.1503/cmaj.150032 